\title{
Hydrogen Arrangements on Defective Quasi-Molecular BN Fragments
}

\author{
Remedios Cortese, ${ }^{\circledR}$ Dario Campisi, ${ }^{\dagger}$ and Dario Duca* ${ }^{*}(0)$ \\ Dipartimento di Fisica e Chimica, Università degli Studi di Palermo, Viale delle Scienze Ed. 17, 90128 Palermo, Italy \\ Supporting Information
}

\begin{abstract}
Considering the ever-increasing interest in metal-free materials, some potential chemical applications of quasi-molecular boron nitride (BN) derivatives were tested. Specifically, the behavior of BN fragments was analyzed when given defects, producing local electron density changes, were introduced by using topological engineering approaches. The inserted structural faults were Schottky-like divacancy (BN-d) defects, assembled in the fragment frame by the subtraction of one pair of $\mathrm{B}$ and $\mathrm{N}$ atoms or Stone-Wales (SW) defects. This study is aimed at highlighting the role of these important classes of defects in BN materials hypothesizing their future

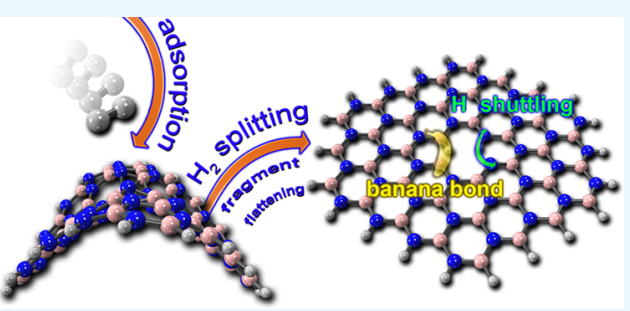
use in $\mathrm{H}_{2}$-based processes, related to either (i) $\mathrm{H}_{2}$ activation or (ii) $\mathrm{H}_{2}$ production, from preadsorbed hydrogenated molecular species on BN sites. Here, it has been observed that BN species, embodying SW defects, are characterized by endothermic $\mathrm{H}_{2}$ adsorption and fragmentation phenomena in order to guess their potential use in processes based on the transformation or production of hydrogen. On the contrary, in the presence of $\mathrm{BN}-\mathrm{d}$ defects, and for reasons strictly related to local structural changes occurring along with the hydrogen rearrangements on the defective BN fragments, a possible use can be inferred. Precautions must be however taken to decrease the material rigidity that could actually decrease the ability of the BN fragment to flatten. This conversely seems to be a necessary requirement to have strong exothermic effects, following the rearrangements of the $\mathrm{H}_{2}$ molecules.
\end{abstract}

\section{INTRODUCTION}

Hexagonal boron nitride (h-BN) materials have attracted special interest in the past years thanks to their excellent thermal and chemical stability. h-BN is the most stable BN species under ambient conditions, and it is a structural analogue of graphene. These two materials share the same twodimensional (2D) honeycomb lattice, but, although the B and $\mathrm{N}$ atomic couple represents the canonical "combo element" ${ }^{1}$ of the $\mathrm{C}$ atom, graphene and h-BN show different electronic properties, the former being a gapless semimetal ${ }^{2,3}$ while the latter almost an insulator with a very large band gap. ${ }^{4,5}$ Also, $\mathrm{BN}$ nanotube (BNNT) and $\mathrm{C}$ nanotube (CNT) materials exhibit unalike conduction behavior. BNNTs are indeed not conductive irrespective of their morphological properties, ${ }^{6,7}$ whereas CNTs are conductive and show band gap changes with the change in the nanotube diameter size. ${ }^{8}$ Several nanostructured h-BN compounds with a lattice characterized by the hexagonal symmetry have been synthesized: nanosheets, ${ }^{9,10}$ nanocones, ${ }^{11}$ nanotubes, ${ }^{12}$ nanohorns, ${ }^{13}$ and nanorods $^{14}$ as well as several nanostructured objects, collectively named nanoflakes.

A vast literature exists on theoretical and experimental studies of hydrogen adsorption on one-dimensional and 2D nanostructures. It was shown that both physisorption and chemisorption of $\mathrm{H}_{2}$ are less energetically favorable on pristine h-BNNT and BNNT than on the carbon counterparts. Furthermore, the presence of topological point defects induces new local configurations in the h-BN pattern, which usually implies the onset of new properties. ${ }^{15,16}$

In this scenario, defects might be relevant for imparting a certain affinity toward hydrogen to the $\mathrm{BN}$ lattices. It was suggested by Schmidt et al. ${ }^{17}$ that the experimental conditions in the synthetic protocols such as the arc discharge or the high temperature generally employed and in the chemical reactions at which the single-walled BNNTs and sheets are grown make point defects-such as vacancies, antisites, and some very common substitutional impurities, such as carbon and/or oxygen-highly probable. Different techniques such as ball milling and plasma etching are also used to introduce defects into BN-based materials. ${ }^{18,19}$ In addition to this, Shevlin and Guo reported that point defects in $h$-BN sheets can be engineered via chemical etching by ammonia and $\mathrm{HCl}$ gases to create vacancies and other natural defects. ${ }^{20}$

High-resolution electron microscopy has directly shown the in situ creation under electron irradiation of point and extended defective structures on single-walled BNNTs. ${ }^{21}$ Interestingly, molecular dynamics simulations were also employed to gain quantitative information on the probabilities of creating different types of defects in h-BN single layers under ion irradiation. ${ }^{16}$

Received: May 18, 2019

Accepted: July 18, 2019

Published: August 30, 2019 
Stone-Wales (SW) and (B,N) divacancy (BN-d) defect topologies are without any doubt among the most common ones in the h-BN-based materials. SW defects originate by the rotation of $90^{\circ}$ of a $\mathrm{B}-\mathrm{N}$ bond that causes, starting from four hexagonal rings, the formation of two pentagonal and two heptagonal rings. BN-d defects are conversely typical examples of Schottky defect pairs, involving one $\mathrm{B}$ and one $\mathrm{N}$ atom. Although in general this pair of charged defects may be spatially distributed, in practice there is a strong electrostatic interaction between the two oppositely charged centers, which is maximized for neighboring sites. It was demonstrated that in the case of the $\mathrm{BN}$ frameworks, once a vacancy is formed, the formation energy for a subsequent neighboring vacancy is close to zero. ${ }^{21}$ Thus, the probability of forming a second neighboring vacancy is higher than at any other site.

In the present investigation, the affinity toward hydrogen of the defective small-/medium-sized $\mathrm{BN}$ polycyclic aromatic analogue saturated with hydrogen, collectively identified as quasi-molecular nanoflake $(q-\mathrm{mn})$ species, was evaluated. In particular, BN $q$-mns bearing BN-d or SW defects were studied as potential hydrogen splitting materials.

The raw idea behind this study mainly originated from the consideration of two analogies existing between graphene-like h-BN compounds and other metal-free materials. In fact, (i) Cortese et al. ${ }^{22}$ have already shown that $\mathrm{N}$-doped carbonaceous defective compounds give rise to largely exergonic $\mathrm{H}_{2}$ fragmentation while (ii), as first reported by Stephan. ${ }^{23}$ Frustrated Lewis pair (FLP) arrangements, similar to those characterizing the $\mathrm{BN}$ defective materials, are extremely active in $\mathrm{H}_{2}$ fragmentation. The intriguing overlap of the features above-both connected to the local electronic-state modifications which are necessary for the catalytic processes and which are more conventionally obtained by the use of metalsupported catalysts ${ }^{24-29}$ - would seem to suggest that the defective $\mathrm{BN}$ nanoflakes could be related to $\mathrm{H}_{2}$ cleavage phenomena and hence to transformation processes involving atomic $\mathrm{H}$, activated by electronic and/or steric frustration phenomena that arise from the presence of topological point defects. This possibility would seem to have been experimentally shown by Nash et al. for defect-laden BN materials, which were actually able to activate both $\mathrm{H}_{2}$ and olefins with measurable catalytic rates. ${ }^{30}$ This finding clearly suggests that not only the chemical nature of the sites, eventually modified by the presence of oxide surface species, ${ }^{31}$ play a role in the catalytic activity of the $\mathrm{BN}$ materials, but also the presence of defects and their local topology can induce catalytic properties in periodic $\mathrm{BN}$ structures. With respect to this, it has here to be recalled that the use of $\mathrm{BN}$ catalytic materials, both as the metal support ${ }^{32-37}$ and as the metal-free species, ${ }^{38}$ is not new in the literature. In particular, the $\mathrm{BN}$ materials were employed for catalytic reactions that involved either the $\mathrm{H}_{2}$ use ${ }^{39}$ and its production $^{40}$ or oxidative dehydrogenation ${ }^{31,41,42}$ and oxidation $^{43}$ processes. However, the systematic exploitation of defective sites in $\mathrm{BN}$ materials for practical aims would represent a rather new approach, whose study could suggest a great deal of potential future applications. In particular, to take into account local effects related to possible deformations of the $\mathrm{BN}$ surface produced by transformations following the $\mathrm{B}$ and $\mathrm{N}$ site interactions with hydrogen species, molecular $\mathrm{BN}$ fragments of different sizes have been studied rather than periodic systems that, by construction, could not easily deviate from their starting graphene-like h-BN structure.

\section{COMPUTATIONAL DETAILS}

All the calculations reported were performed either by a pure quantum mechanics (QM) or by a hybrid quantum mechanics $(\mathrm{QM}) /$ molecular mechanics (MM) approach, framed in an ONIOM energy extrapolation scheme. ${ }^{44} \mathrm{QM}$ calculations were in any cases set within the density functional theory (DFT). Differently sized BN polycyclic molecular systems, saturated with hydrogen atoms, were calculated by pure QM approaches. Truncated armchair nanotubes, saturated by hydrogen atoms, were conversely calculated by QM/MM ONIOM approaches.

Gaussian $09^{45}$ was the suite of codes employed in this study. In both the pure QM and the hybrid QM/MM approaches, the exchange-correlation functional selected was M06-L, ${ }^{46}$ associated with the correlation-consistent polarized double zeta basis set, cc-pVDZ, while according to the MM level of theory, the universal force field ${ }^{47}$ was chosen. All the geometries of intermediates and transition states were, respectively, optimized and characterized as minimum or saddle points on the potential energy surface with the analysis of the frequencies calculated within the harmonic approximation. In particular, the transition states were located by means of the optimized Berny algorithm, as implemented in Gaussian 09.

The reaction energy $\left(\Delta E_{\mathrm{r}}\right)$ was calculated as the difference between the energy of products and reactants of a given molecular event. The activation barrier $\left(\Delta E_{\mathrm{a}}\right)$ was instead intended as the difference between the energy of a given transition state and that of the species preceding it. All the energies reported in this study included the zero-point energy contribution.

The $q$-mns were built starting from the h-BN lattice; as models representing the pristine $\mathrm{BN}$-based nanoflakes, two differently extended fragments with stoichiometries $\mathrm{B}_{21} \mathrm{~N}_{21} \mathrm{H}_{16}$ and $\mathrm{B}_{40} \mathrm{~N}_{40} \mathrm{H}_{22}$ were evaluated and specified as $\mathrm{BN}-\mathrm{I}$ and $\mathrm{BN}$ II, respectively. SW defects were introduced in the $\mathrm{BN} q$-mns above, obtaining the models SWBN-I and SWBN-II (see Figure 1a,b). Atom numbering belonging to the defective configuration is shown in Figure 1c.

The models including $\mathrm{BN}-\mathrm{d}$ defects were obtained by removing one adjacent $(B, N)$ couple from the hexagonal framework of the pristine BN-I and BN-II nanoflakes. The resulting fragments characterized by the $\mathrm{B}_{20} \mathrm{~N}_{20} \mathrm{H}_{16}$ and $\mathrm{B}_{39} \mathrm{~N}_{39} \mathrm{H}_{22}$ stoichiometries are identified as DVBN-I and DVBN-II, respectively (see Figure 2a,b).

The SWBNNT and DVBNNT fragments bearing SW and $\mathrm{BN}$-d defects, respectively, were employed to account for the effect of the curvature of the $\mathrm{BN}$ framework (see Figures 3 and 4 ). Both these fragments were obtained by a single-walled armchair $(12,12)$ truncated nanotube, saturated by hydrogen atoms and having a length of $20.9 \AA$. They were individually analyzed by an ONIOM QM/MM approach. In both fragments, the ONIOM model system was the central portion of the nanotube, whereas the real system was the central portion of the whole nanotube. In particular, the SWBNNT and DVBNNT model systems were singularly characterized by a $\mathrm{B}_{40} \mathrm{~N}_{40}$ and a $\mathrm{B}_{39} \mathrm{~N}_{39}$ stoichiometry, respectively. Finally, in the SWBNNT model, the position of the defect was chosen considering that SW defects are less stable when oriented along the main axis of the nanotube. ${ }^{48}$ 


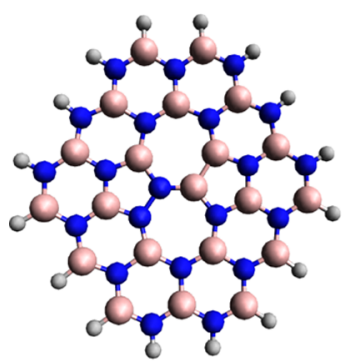

(a)

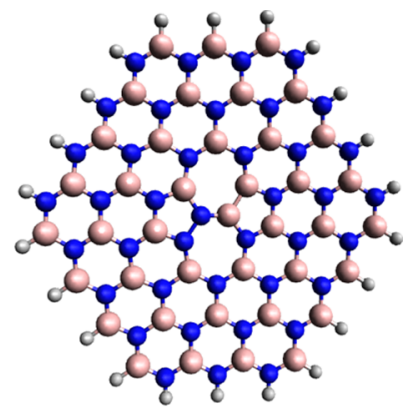

(b)

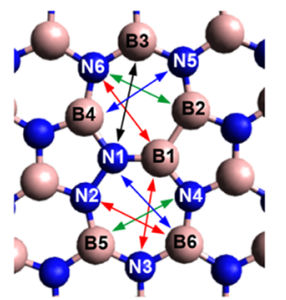

(c)

Figure 1. Optimized geometry of SWBN-I (a) and SWBN-II (b) q$\mathrm{mns}$ and numbering of the atomic centers (c), characterizing SW defects. N, B, and $\mathrm{H}$ atoms are given in the order: blue, pink, and gray.

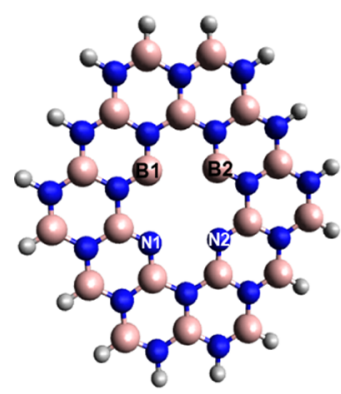

(a)

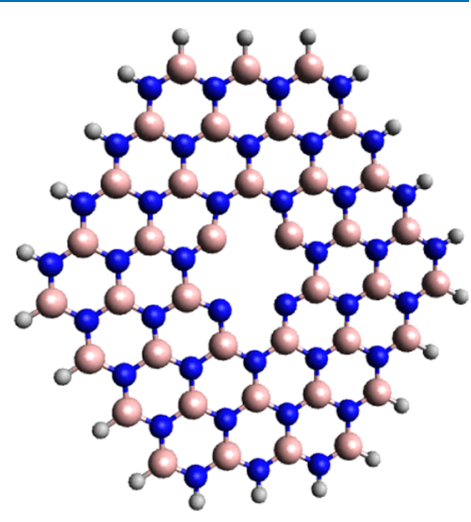

(b)
Figure 2. Starting geometries of DVBN-I (a) and DVBN-II (b) qmns. The essential numbering of the $\mathrm{BN}-\mathrm{d}$ defect model is represented in the DVBN-I fragment. N, B, and $\mathrm{H}$ atoms are given in the order: blue, pink, and gray.

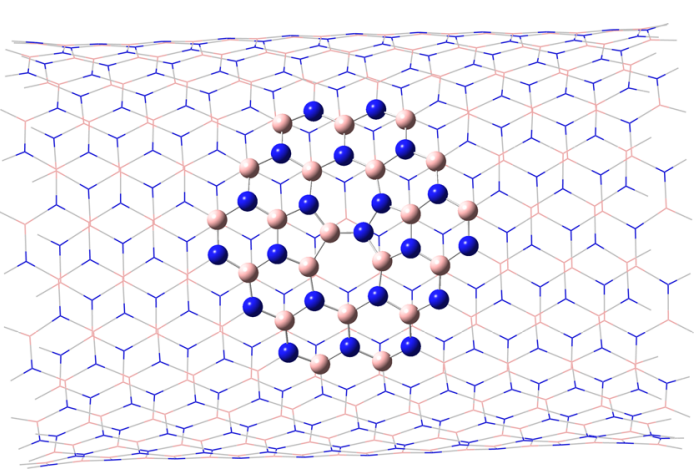

Figure 3. ONIOM-optimized single-walled armchair $(12,12)$ SWBNNT fragment. The ONIOM model system is reported in ball-and-stick. N, B, and $\mathrm{H}$ atoms are given in the order: blue, pink, and gray.

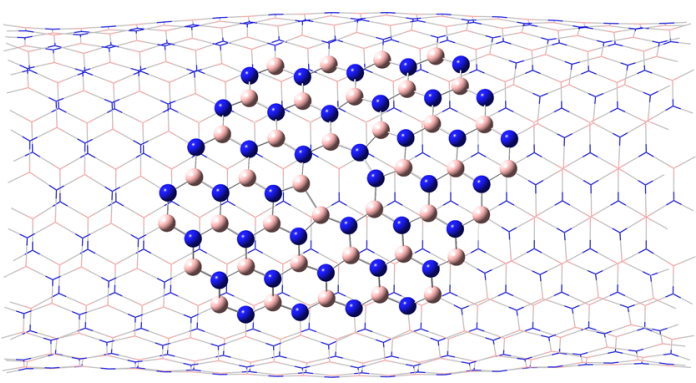

Figure 4. ONIOM-optimized single-walled armchair $(12,12)$ DVBNNT fragment. The ONIOM model system is reported in ball-and-stick. N, B, and $\mathrm{H}$ atoms are given in the order: blue, pink, and gray.

\section{RESULTS AND DISCUSSION}

3.1. $\mathrm{H}_{2}$ Splitting on Pristine BN Nanoflakes. The $\Delta E_{\mathrm{r}}$ values associated with the $\mathrm{H}_{2}$ fragmentation processes, occurring in correspondence of adjacent pairs of $\mathrm{B}$ and $\mathrm{N}$ atoms $(|\mathrm{B} n, \mathrm{~N} m|)$, were calculated for both the $\mathrm{BN}-\mathrm{I}$ and $\mathrm{BN}-\mathrm{II}$ fragments. These processes, irrespective of $\mathrm{n}$ and $\mathrm{m}$, showed to be highly endothermic and almost isoenergetic, resulting in the involved energies of ca. 213 and $216 \mathrm{~kJ} \mathrm{~mol}^{-1}$ for the smaller and larger fragments, respectively. This finding is in line with other studies present in the literature. As an example, Shevlin and $\mathrm{Guo}^{20}$ reported a reaction energy of $1.95 \mathrm{eV}$ for the hydrogen chemisorption on pristine h-BN. Considering the literature data and in agreement with our results, it is furthermore remarkable that the increase of the $\mathrm{BN}$ framework size, going from $q$-mns to "infinite" sheets, has a negligible effect on the $\Delta E_{\mathrm{r}}$ values. For the sake of comparison, it is useful to point out that also on graphene the hydrogen fragmentation is highly endothermic, as already demonstrated by McKay et al. ${ }^{49}$ which evaluated for this process a reaction heat equal to $1.89 \mathrm{eV}$.

3.2. $\mathrm{H}_{2}$ Splitting on BN Fragments Bearing SW Defects. The presence of one SW defect determines the formation of two heptagonal and two pentagonal rings, in which several nonadjacent pairs of $\mathrm{B}$ and $\mathrm{N}$ atoms $(\mathrm{B} n \mid \mathrm{N} m)$ are present, which are not topologically equivalent (see doubleheaded arrows in Figure 1c). The distances as well as the geometrical arrangements that characterize these different atom pairs could in principle activate FLP chemistry. ${ }^{50,51}$ According to this, the introduced SW defects might influence the $\mathrm{H}_{2}$ splitting processes, which further could also be influenced by the curvature and size of the BN fragments that frame the point defect.

In order to validate these inferences and, in particular, to verify if it is possible to pick out preferential $\mathrm{H}_{2}$ chemisorption constellations, $\mathrm{H}_{2}$ splitting $\Delta E_{\mathrm{r}}$ values were calculated for the $\mathrm{BN}$ models that include SW defects on the eight different $\mathrm{B} n \mathrm{l}$ $\mathrm{N} m$ pairs above. The hydrogenated SWBN-I model after optimization showed a slight local pyramidalization/extraction of both the hydrogenated boron or nitrogen sites, as illustrated by either the dihedral angles $\theta(\mathrm{B} n)$ or $\theta(\mathrm{N} m)$, reported in Table 1. These dihedral angles were singularly identified, considering at first the hydrogenated $\mathrm{B}$ or $\mathrm{N}$ atom showing the hydrogen atoms in an antiperiplanar configuration and then the subsequent (and clockwise consecutive) three nonhydrogenated atoms of the heptagonal cycle (see Figure 5). Table 1, both for the smaller SWBN-I model and for the larger SWBN-II model, also outlines the distances of the nonadjacent 
Table 1. Hydrogenated SWBN-I and SWBN-II Fragments: Distances, $d_{\mathrm{B} n \mid \mathrm{N} m}$, and Dihedral Angles, $\boldsymbol{\theta}(\mathrm{B} n)$ and $\boldsymbol{\theta}(\mathrm{N} m)$, of the Nonadjacent $\mathrm{B} n \mid \mathrm{Nm}$ Pairs Involved in the $\mathrm{H}_{2}$ Splitting Process and the Corresponding Fragmentation Energy, $\Delta E_{\mathrm{r}}$

\begin{tabular}{|c|c|c|c|c|}
\hline $\mathrm{B} n \mid \mathrm{N} m^{a}$ & $d_{\mathrm{B} n \mid \mathrm{N} m}(\AA)$ & $\theta(\mathrm{B} n)(\mathrm{deg})$ & $\theta(\mathrm{N} m)(\mathrm{deg})$ & $\Delta E_{\mathrm{r}}\left(\mathrm{kJ} \mathrm{mol}{ }^{-1}\right)$ \\
\hline \multicolumn{5}{|c|}{ SWBN-I } \\
\hline $\mathrm{B} 5 \mid \mathrm{N} 4$ & 3.22 & 169.3 & 179.3 & 263.8 \\
\hline $\mathrm{B} 2 \mathrm{|N} 6$ & 3.24 & 177.7 & 169.4 & 262.1 \\
\hline $\mathrm{B} 1 \mathrm{~N} 3$ & 3.39 & 176.1 & 167.7 & 238.3 \\
\hline $\mathrm{B} 6 \mid \mathrm{N} 2$ & 3.40 & 160.9 & 179.5 & 258.3 \\
\hline B4|N5 & 3.43 & 154.1 & 170.5 & 277.0 \\
\hline $\mathrm{B} 6 \mid \mathrm{N} 1$ & 3.44 & 161.0 & 168.6 & 257.8 \\
\hline B1IN6 & 3.45 & 168.5 & 178.5 & 250.5 \\
\hline $\mathrm{B} 3 \mid \mathrm{N} 1$ & 3.70 & 165.3 & 162.5 & 263.8 \\
\hline \multicolumn{5}{|c|}{ SWBN-II } \\
\hline $\mathrm{B} 1 \mid \mathrm{N} 3$ & 3.37 & -162.5 & 162.2 & 223.6 \\
\hline B4|N5 & 3.43 & 178.9 & 161.3 & 259.3 \\
\hline
\end{tabular}

${ }^{a}$ For the numbering of the nonadjacent $\mathrm{B}$ and $\mathrm{N}$ atom pairs, see Figure 1c.

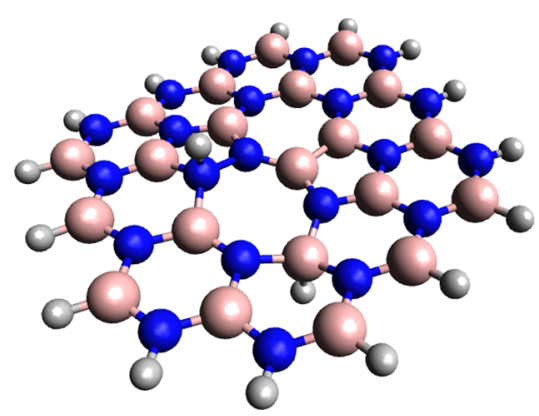

Figure 5. Optimized geometries of hydrogenated SWBN-I $q$-mns: the $\mathrm{H}_{2}$ antiperiplanar configuration is evident. $\mathrm{N}, \mathrm{B}$, and $\mathrm{H}$ atoms are given in the order: blue, pink, and gray.

$\mathrm{B} n \mid \mathrm{N} m$ pairs $\left(d_{\mathrm{B} n \mid \mathrm{N} m}\right)$ and the corresponding $\mathrm{H}_{2}$ splitting energy, both reported in the order of increasing $d_{\mathrm{B} n \mid \mathrm{N} m}$ values (from 3.22 to $3.70 \AA$ ).

The structural features of the different $\mathrm{B} n \mid \mathrm{N} m$ hydrogenated pairs are almost invariant, irrespective of the considered positions, as well as the $\mathrm{H}_{2}$ splitting energy behavior on the same defective positions is invariant. This is, of course, a clear indication that preferential SW binding sites do not exist in this BN fragment. In particular, fragmentation is in any case highly endothermic, spanning the reaction energy in between ca. 240 and $260 \mathrm{~kJ} \mathrm{~mol}^{-1}$. Noticeably, the $\Delta E_{\mathrm{r}}$ values are regularly higher than the one found for the pristine $\mathrm{BN} q$-mns.

For the sake of completeness, three adjacent $|\mathrm{B} n, \mathrm{~N} m|$ pairs of the SWBN-I model were analyzed, namely, $|\mathrm{B} 1, \mathrm{~N} 1|$, $|\mathrm{B} 3, \mathrm{~N} 5|$, and $|\mathrm{B} 5, \mathrm{~N} 3|$. The $\Delta E_{\mathrm{r}}$ values on these pairs of sites are obtained in the order: 144.7, 122.2, and $139.9 \mathrm{~kJ} \mathrm{~mol}^{-1}$. Although to a lesser respect to the nonadjacent $\mathrm{B} n \mid \mathrm{N} m$ pairs, in this case the $\mathrm{H}_{2}$ splitting energy is invariably endothermic. The $\Delta E_{\mathrm{r}}$ values of the adjacent $|\mathrm{B} n, \mathrm{~N} m|$ pairs are also smaller compared to those of the adjacent pairs of the pristine fragments. This is in line with the results of $\mathrm{Li}$ et al., which demonstrated that the $\mathrm{B}-\mathrm{N}$ bonds, adjacent to the $\mathrm{B}-\mathrm{B}$ and $\mathrm{N}-\mathrm{N}$ bonds, are more reactive when the SW defect is framed within a series of zigzag $(n, 0)$ single-walled BNNTs. ${ }^{52}$

The size effects of the $\mathrm{BN}$ model on the $\mathrm{H}_{2}$ splitting occurring on the SW defects were investigated by adsorbing a couple of $\mathrm{H}$ atoms on the SWBN-II model, which is almost double with respect to the SWBN-I one. The splitting process was studied considering only the nonadjacent B1IN3 and B4l N5 pairs. The latter were selected because in the SWBN-I model, it was not possible to individuate preferential adsorption sites, while in the same model, the selected pairs of sites showed the lower and higher $\Delta E_{\mathrm{r}}$ values, respectively. Therefore, they could be considered representative of the whole properties of the SW defect sites of the larger model. Indeed, significant changes, as shown in Table 1 , were not observed either in the structural features or in the reaction energies.

In order to evaluate the curvature effects of BN fragments on the $\mathrm{H}_{2}$ splitting processes occurring on SW defects, the SWBNNT tubular model was considered. In particular, the $\mathrm{H}_{2}$ molecule was fragmented on the same nonadjacent $\mathrm{B} n \mid \mathrm{Nm}$ atom pairs already investigated for the SWBN-I model. The comparison of the results, reported in Tables 1 and 2, shows that the $d_{\mathrm{Bn} \mid \mathrm{N} m}$ values in the SWBNNT model are slightly shorter than those found for the SWBN-I and SWBN-II models, while the $\Delta E_{\mathrm{r}}$ values are on the whole smaller.

Table 2. Hydrogenated SWBNNT Fragments: Distances, $d_{\mathrm{B} n \mid \mathrm{N} m}$, and Dihedral Angles, $\boldsymbol{\theta}(\mathrm{B} n)$ and $\boldsymbol{\theta}(\mathrm{Nm})$, of the Nonadjacent $\mathrm{B} n \mid \mathrm{Nm}$ Pairs Involved in the $\mathrm{H}_{2}$ Splitting Process and the Corresponding Fragmentation Energy, $\Delta E_{\mathrm{r}}$

\begin{tabular}{|c|c|c|c|c|}
\hline $\mathrm{B} n \mid \mathrm{N} m^{a}$ & $d_{\mathrm{B} n \mid \mathrm{N} m}(\AA)$ & $\theta(\mathrm{B} n)(\mathrm{deg})$ & $\theta(\mathrm{N} m)(\mathrm{deg})$ & $\Delta E_{\mathrm{r}}\left(\mathrm{kJ} \mathrm{mol}{ }^{-1}\right)$ \\
\hline \multicolumn{5}{|c|}{ SWBNNT } \\
\hline B2IN6 & 2.95 & 174.4 & 178.4 & 212.3 \\
\hline B5IN4 & 2.97 & 162.4 & 171.9 & 212.0 \\
\hline B4|N5 & 3.05 & 178.1 & 165.2 & 233.0 \\
\hline $\mathrm{B} 6 \mid \mathrm{N} 2$ & 3.18 & 14.4 & 171.6 & 223.1 \\
\hline B1IN6 & 3.20 & 173.1 & 179.8 & 242.5 \\
\hline $\mathrm{B} 6 \mid \mathrm{N} 1$ & 3.20 & 178.1 & 169.8 & 280.1 \\
\hline $\mathrm{B} 1 \mid \mathrm{N} 3$ & 3.43 & 171.2 & 174.6 & 234.4 \\
\hline $\mathrm{B} 3 \mid \mathrm{N} 1$ & 3.69 & 157.2 & 173.1 & 290.1 \\
\hline
\end{tabular}

${ }^{a}$ For the numbering of the nonadjacent $\mathrm{B}$ and $\mathrm{N}$ atom pairs, see Figure 1c.

The curvature effects were even evaluated on adjacent couples of $\mathrm{B}$ and $\mathrm{N}$ atoms of the SWBNNT model. The resultant $\Delta E_{\mathrm{r}}$ for the $|\mathrm{B} 1, \mathrm{~N} 1|,|\mathrm{B} 3, \mathrm{~N} 5|$, and $|\mathrm{B} 5, \mathrm{~N} 3|$ were in the order: $246.1,150.1$, and $176.9 \mathrm{~kJ} \mathrm{~mol}^{-1}$. These are higher than those found for the SWBN-I model, while the former value is somehow also out of behavior. Overall, however, the whole image has not changed, irrespective of the model considered: $\mathrm{H}_{2}$ fragmentation is clearly strongly endothermic on sites related to the formation of SW defects on BN $q-\mathrm{mn}$ materials. Thus, they would seem to be quite different with respect to the SW carbonaceous defect analogues. These, as found out by Letardi et al., ${ }^{53}$ are actually able to easily accommodate $\mathrm{H}$ atoms, producing exothermic transformations, hence locally freeing a large amount of energy.

3.3. $\mathrm{H}_{2}$ Splitting on BN Fragments Bearing Divacancy Defects. 3.3.1. Reconstruction of Bonds. In a given framework, the existence of unsaturated atoms usually implies the possibility of bond reconstructions. For this reason, once the divacancy in the $q$-mns is created, this phenomenon was taken into account and investigated.

Two types of reconstructions were considered. In the first construction, DVBN-I $\{4,10,4\}_{R}$ model of Figure $6 \mathrm{a}$, the nanoflake shows two newly formed $\mathrm{B}-\mathrm{N}$ bonds, at once 

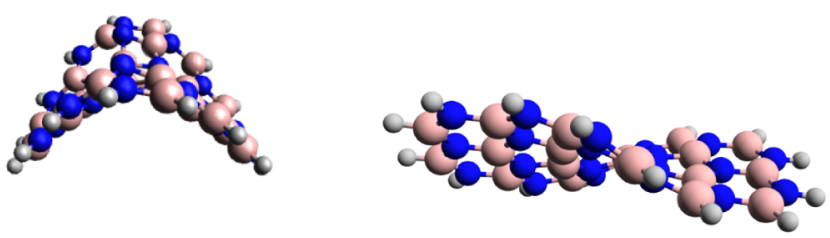

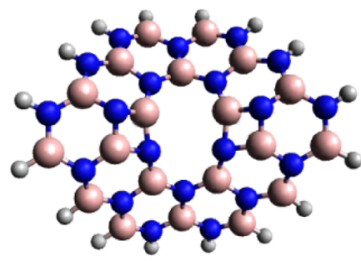

(a)

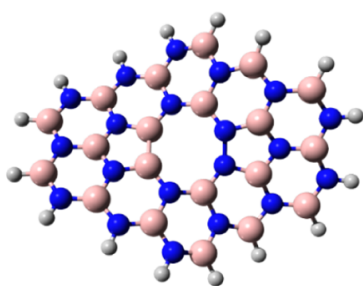

(b)
Figure 6. Optimized geometry of the reconstructed DVBN-I $\{4,10,4\}_{R}$ (a) and DVBN-I $\{5,8,5\}_{\mathrm{R}}$ (b) nanoflakes. The first underwent $2 \mathrm{~B}-\mathrm{N}$ bond reconstructions, whereas the second underwent $1 \mathrm{~B}-\mathrm{B}$ and 1 $\mathrm{N}-\mathrm{N}$. Side and face views of the fragments are reported in the upper and lower parts of the panel, respectively. $\mathrm{N}, \mathrm{B}$, and $\mathrm{H}$ atoms are given in the order: blue, pink, and gray.

shaping 2 four-terms and 1 ten-terms cycles. In the second construction, DVBN-I $\{5,8,5\}_{\mathrm{R}}$ model of Figure $6 \mathrm{~b}, 1 \mathrm{~B}-\mathrm{B}$ and $1 \mathrm{~N}-\mathrm{N}$ bonds appear with the concomitant shaping of 2 fiveterms and 1 eight-terms cycles. The $\{5,8,5\}_{R}$ reconstructed model was found to be more stable than the $\{4,10,4\}_{R}$ one of $45.5 \mathrm{~kJ} \mathrm{~mol}^{-1}$, thus agreeing with the findings already reported by Zobelli et al. ${ }^{21}$

The formation of homonuclear bonds, as a consequence of the reconstruction of defective $\mathrm{BN}$ frameworks, was largely debated in the literature. The first studies suggested that the formation of $\mathrm{B}-\mathrm{B}$ and $\mathrm{N}-\mathrm{N}$ bonds was quite critical. In particular, Saito and Maida suggested that rings with an even number of sides (e.g., squares, hexagons, and octagons) preserved the original $\mathrm{B}-\mathrm{N}$ bonds, while odd-numbered rings (e.g., pentagons and heptagons) allowed the introduction of either $\mathrm{B}-\mathrm{B}$ or $\mathrm{N}-\mathrm{N}$ bonds. ${ }^{54}$ More recently, it was conversely demonstrated that the formation of homonuclear bonds in $\mathrm{BN}$ fragments is very common. In fact, as an example, Sinthika et al. calculated the thermodynamic properties and vibrational spectra of $\mathrm{BN}-60$ fullerene-like cages, suggesting that higher number of homonuclear $\mathrm{N}-\mathrm{N}$ bonds and lower $\mathrm{B} / \mathrm{N}$ atomic ratios resulted in more stable configuration structures. Interestingly, it was also suggested that the presence of homonuclear bonds bestow the system with salient catalytic properties. $^{55}$

All the pristine h-BN nanoflakes as well as the ones already discussed framing SW defects are planar, whereas the reconstructed $q$-mns always show strong deviations from planarity. Anyhow, the $\{4,10,4\}$ and $\{5,8,5\}$ reconstructions generate two different kinds of curved structures. In the first $\{4,10,4\}$ reconstruction, the resulting nanoflake has the shape of a hyperbolic paraboloid, whereas in the second $\{5,8,5\}$ reconstruction, the resulting nanoflake has the shape of a hyperbolic tangent. This phenomenon is clearly related to the occurrence of cycles with either four or five terms that in honeycomb structures induce deviations from the planarity, as already demonstrated by Miller and Owens.. ${ }^{56}$

The DVBN-II fragment has a size almost double with respect to that of the DVBN-I one, but in the case of the larger
DVBN-II model, the presence of $\mathrm{BN}-\mathrm{d}$ defects generates remarkable structural changes. However, at variance with the DVBN-I fragment, the DVBN-II one, besides the minima corresponding to the $\{4,10,4\}$ and $\{5,8,5\}$ reconstructions, was characterized by a minimum on its potential energy surface even when the bond reconstructions did not occur (see Figure 7). In this case, the fragment retained its planarity as illustrated

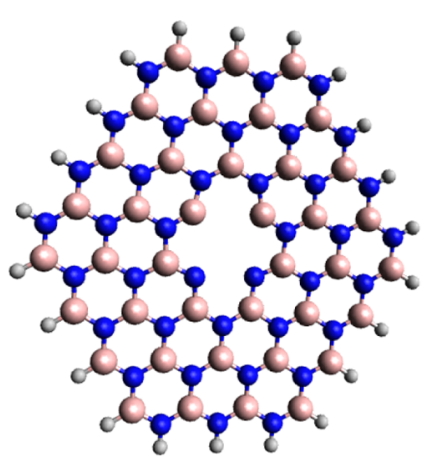

(a)
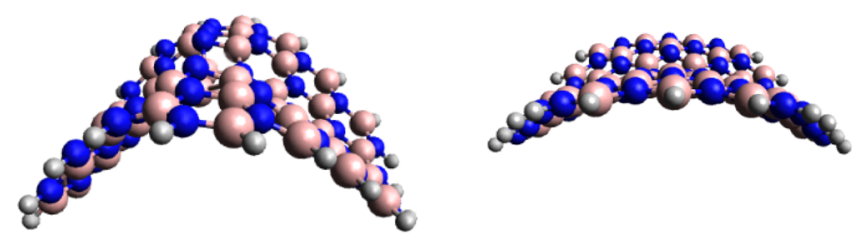

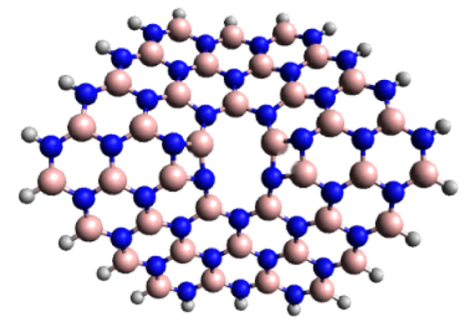

(b)

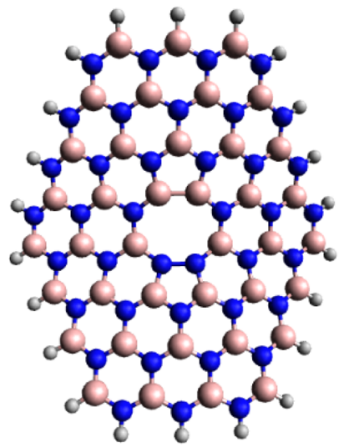

(c)
Figure 7. Optimized geometry of the DVBN-II (a), DVBN$\operatorname{II}\{4,10,4\}_{R}(b)$, and DVBN-II $\{5,8,5\}_{R}$ (c) fragments: the first did not show any bond reconstruction, the second showed $2 \mathrm{~B}-\mathrm{N}$ bond reconstructions, and the third showed $1 \mathrm{~B}-\mathrm{B}$ and $1 \mathrm{~N}-\mathrm{N}$ bond reconstructions. For the second (b) and third (c) q-mn, side and face views are reported in the upper and lower parts, respectively. N, B, and $\mathrm{H}$ atoms are given in the order: blue, pink, and gray.

by the values of the $\theta(\mathrm{B} n)$ and $\theta(\mathrm{Nm})$ dihedral angles, reported in Table 3 . These dihedral angles actually would seem to show just slight misalignments of the unsaturated atoms constituting the divacancy. The reconstructed DVBN-II$\{4,10,4\}_{R}$ and DVBN-II $\{5,8,5\}_{R}$ nanoflakes have features very similar to those of the analogue DVBN-I ones (see Figure $7 \mathrm{~b}, \mathrm{c})$. In particular, the $\mathrm{B}-\mathrm{B}$ and $\mathrm{N}-\mathrm{N}$ bond lengths are equal to 1.75 and $1.50 \AA$, compared with those reported by Zobelli et al. (1.93 and $1.74 \AA$ ) for the same bonds, in larger planar models. ${ }^{18}$ Indeed, this comparison would seem to confirm that the reconstruction is more effective when the $\mathrm{BN}$ framework is 
Table 3. DVBN-II, DVBN-II $\{4,10,4\}_{R}$, and DVBNII $\{5,8,5\}_{\mathrm{R}}$ Fragments: Distances, $d_{\mathrm{B} n \mid \mathrm{N} m}$, and Dihedral Angles, $\boldsymbol{\theta}(\mathrm{B} n)$ and $\boldsymbol{\theta}(\mathrm{Nm})$, of Nonadjacent $\mathrm{B} n \mid \mathrm{N} m$ Site Pairs Involved in the Reconstruction of BN $q$-mns after Divacancy Formation

$\begin{array}{cccc}\mathrm{B} n \mid \mathrm{N} m^{a} & d_{\mathrm{B} n \mid \mathrm{N} m}(\AA) & \theta(\mathrm{B} n)(\mathrm{deg}) & \theta(\mathrm{N} m)(\mathrm{deg}) \\ & \text { DVBN-II } & & \\ \mathrm{B} 1 \mid \mathrm{N} 1 & 2.76 & -172.6 & 170.8 \\ \mathrm{~B} 2 \mid \mathrm{N} 2 & 2.76 & -172.6 & 170.8 \\ \mathrm{~B} 1 \mid \mathrm{N} 2 & 4.08 & -172.6 & 170.8 \\ \mathrm{~B} 2 \mid \mathrm{N} 1 & 4.08 & -172.6 & 170.8 \\ \mathrm{DVBN}-\mathrm{II}\{\mathbf{4 , 1 0 , 4}\}_{\mathrm{R}} & & \\ \mathrm{B} 1 \mid \mathrm{N} 1 & 1.48 & 173.4 & -178.1 \\ \mathrm{~B} 2 \mid \mathrm{N} 2 & 1.48 & -178.2 & 175.3 \\ \mathrm{~B} 1 \mid \mathrm{N} 2 & 3.31 & 173.4 & 175.3 \\ \mathrm{~B} 2 \mid \mathrm{N} 1 & 3.30 & -178.2 & -178.1 \\ \mathrm{DVBN}-\mathrm{II}\{\mathbf{5 , 8 , 5}\}_{\mathrm{R}} & & \\ \mathrm{B} 1 \mid \mathrm{N} 1 & 3.13 & 166.6 & -159.0 \\ \mathrm{~B} 2 \mid \mathrm{N} 2 & 3.13 & -166.6 & 159.0 \\ \mathrm{~B} 1 \mid \mathrm{N} 2 & 3.52 & 166.6 & 159.0 \\ \mathrm{~B} 2 \mid \mathrm{N} 1 & 3.52 & -166.6 & -159.0\end{array}$

${ }^{a}$ For the numbering of the nonadjacent $\mathrm{B}$ and $\mathrm{N}$ atom pairs, see Figure 2a.

smaller and hence more flexible and prone to geometry changes. ${ }^{18}$

The DVBN-II $\{5,8,5\}_{\mathrm{R}}$ structure obtained through the reconstruction of $\mathrm{B}-\mathrm{B}$ and $\mathrm{N}-\mathrm{N}$ bonds was found to be the most stable one, followed by that of the reconstructed DVBNII $\{4,10,4\}_{R}$ fragment characterized by the reconstruction of B$\mathrm{N}$ bonds (actually, less stable of ca. $10 \mathrm{~kJ} \mathrm{~mol}^{-1}$ ). The nonreconstructed DVBN-II species was found to be less stable of over $300 \mathrm{~kJ} \mathrm{~mol}^{-1}$ with respect to the most stable DVBN$\mathrm{II}\{5,8,5\}_{\mathrm{R}}$.

Lattice reconstruction phenomena were also mentioned for the periodic $\mathrm{h}-\mathrm{BN}$ lattice and nanotubes having various curvatures. $^{21}$ In particular, it was demonstrated that in the presence of $\mathrm{BN}-\mathrm{d}$ defects, the appearance of homonuclear bonds, that is, of chemical frustration, is energetically more favorable than the steric frustration produced by smaller rings that are accompanied by lattice configurations able to preserve the alternate boron-nitrogen pattern. ${ }^{57}$ Thus, the reconstruction-although influenced, in its effectiveness, by the BN fragment size (see above)-would seem, in any case, to be a process, which on the whole occurs irrespective from the size of the considered BN framework.

In order to evaluate the effect of the curvature on the reconstruction processes, the DVBNNT model of Figure 4 was investigated. Only the $\{5,8,5\}$ reconstruction was taken into account because it resulted in a stable fragment. Indeed, regardless of the considered geometrical initial guess of the model system (i.e., either considering the reconstructed DVBN-II $\{4,10,4\}_{R}$ and DVBN-II $\{5,8,5\}_{R}$ or the nonreconstructed DVBN-II fragment) the optimized geometry always converged to the $\{5,8,5\}$ configuration. The structural features of the optimized DVBNNT fragment are reported in Table 4. These features are similar to those reported for the reconstructed $q$-mns. Specifically, the formed $\mathrm{B}-\mathrm{B}$ and $\mathrm{N}-\mathrm{N}$ bonds, following the reconstruction, became 1.75 and $1.51 \AA$, respectively.

3.3.2. $\mathrm{H}_{2}$ Adsorption on Divacancy Defect Constellations. In this section, the energetics for the hydrogenation process of
Table 4. DVBNNT Model: Distances, $d_{\mathrm{B} n \mid \mathrm{N} m}$, and Dihedral Angles, $\boldsymbol{\theta}(\mathrm{B} n)$ and $\boldsymbol{\theta}(\mathrm{Nm})$, of the Nonadjacent $\mathrm{B} n \mid \mathrm{Nm}$ Pairs Involved in the $\{5,8,5\}$ Reconstruction of the BN Tubular Fragment after Divacancy Formation

$\begin{array}{rrrr}\mathrm{B} n \mid \mathrm{N} m^{a} & d_{\underline{\mathrm{B}} \mid \mathrm{N} m}(\AA) & \theta(\mathrm{B} n)(\mathrm{deg}) & \theta(\mathrm{N} m)(\mathrm{deg}) \\ & \text { DVBNNT } & & \\ \mathrm{B} 1 \mid \mathrm{N} 1 & 3.13 & 167.3 & -154.6 \\ \mathrm{~B} 2 \mid \mathrm{N} 2 & 3.17 & -160.1 & 157.7 \\ \mathrm{~B} 1 \mid \mathrm{N} 2 & 3.49 & 167.3 & 157.7 \\ \mathrm{~B} 2 \mid \mathrm{N} 1 & 3.53 & -160.1 & -154.6\end{array}$

${ }^{a}$ For the numbering of the nonadjacent $\mathrm{B}$ and $\mathrm{N}$ atom pairs, see Figure 2a.

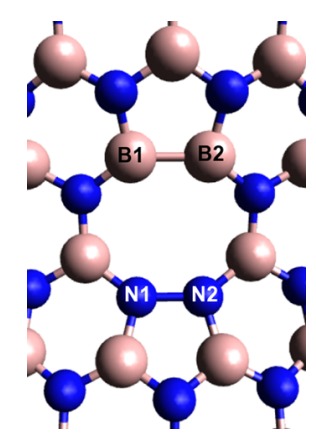

Figure 8. Details and numbering of the DVBN-I $\{5,8,5\}_{R}$ optimized fragment. The whole preoptimized geometry is reported in Figure 2.

topologically nonequivalent $\mathrm{B} n \mid \mathrm{N} m$ nonadjacent pairs, present in the $\{5,8,5\}$ reconstructed divacancy models, is analyzed. The choice of these models was determined by their relative stability with respect to that of the $\{4,10,4\}$ ones. The evaluated molecular event can be sketched as in the following

$$
\operatorname{DVBN}\{5,8,5\}_{\mathrm{R}}+\mathrm{H}_{2} \rightarrow \mathrm{H} / \mathrm{DVBN}-\mathrm{X}\{5,8,5\}_{\mathrm{R}}
$$

with $\mathrm{X}=\mathrm{I}$, II, and $\mathrm{H} / \mathrm{DVBN}-\mathrm{X}\{5,8,5\}_{\mathrm{R}}$, which represents the hydrogenated species either of the DVBN-I $\{5,8,5\}_{R}$ or the DVBN-II $\{5,8,5\}_{R}$ nanoflakes, irrespective of the defective sites occupied by the hydrogens. According to the site numbering of Figure 8 , the $\mathrm{B} 1|\mathrm{~N} 1, \mathrm{~B} 2| \mathrm{N} 2, \mathrm{~B} 2 \mid \mathrm{N} 1$, and $\mathrm{B} 1 \mid \mathrm{N} 2$ couples are those that can be hydrogenated. The $\mathrm{B} 1 \mid \mathrm{N} 1$ and $\mathrm{B} 2 \mid \mathrm{N} 2$ as well as the $\mathrm{B} 1 \mid \mathrm{N} 2$ and $\mathrm{B} 2 \mid \mathrm{N} 1$ couples are topologically equivalent. Thus, although the B2IN2 system will also be shortly discussed, only one of these pairs for each topological equivalent case, namely, B1|N1 and B1|N2, will be further considered. The corresponding hydrogenated fragments will be labeled as $\mathrm{H} /$ DVBN-X\{5,8,5 $\}_{\mathrm{R} 11}$ and H/DVBN-X $\{5,8,5\}_{\mathrm{R} 12}$ (with $\mathrm{X}=\mathrm{I}$, II), respectively.

Because it is well documented that the $\mathrm{H}_{2}$ fragmentation on both metal-based and metal-free materials might induce changes in the multiplicity of the system, ${ }^{22,58}$ the geometries of the different species were optimized in both singlet and triplet states.

The singlet H/DVBN-I $\{5,8,5\}_{\mathrm{R} 11}$ species was found to be a minimum on the potential energy surface, whereas, irrespective of the guess made for the geometry optimization, in the triplet state without exception it converged to the H/DVBN$\mathrm{I}\{5,8,5\}_{\mathrm{R} 12}$ fragment. Conversely, it was not possible to find a minimum on the potential energy surface for the H/DVBN$\mathrm{I}\{5,8,5\}_{\mathrm{R} 12}$ singlet state that invariably converged either to the $\mathrm{H} / \mathrm{DVBN}-\mathrm{I}\{5,8,5\}_{\mathrm{R} 11}$ or to its isoenergetic specular isomer, $\mathrm{H} /$ DVBN-I $\{5,8,5\}_{\mathrm{R} 22}$, characterized by the $\mathrm{B} 2 \mathrm{|N} 2$ nonadjacent pair hydrogen capture. 
$\mathrm{H} / \mathrm{DVBN}-\mathrm{II}\{5,8,5\}_{\mathrm{R} 11}$ was found to be a minimum both in the singlet state and in the triplet state. Anyhow, the difference in energy between these structures was quite relevant, with a more stable singlet state of ca. $165 \mathrm{~kJ} \mathrm{~mol}^{-1}$. Finally, the $\mathrm{H} /$ DVBN-II $\{5,8,5\}_{\mathrm{R} 12}$ species was found to be a minimum only in the triplet state.

These lines of evidence, on the whole, suggest that, irrespective of the $\mathrm{BN}$ fragment size and of the defective $\mathrm{B} n \mathrm{l}$ $\mathrm{Nm}$ site pair topology, the singlet state is consistently the most stable, with the triplet state being associated only with highenergy states. Besides this, another aspect deserves our consideration: the local geometry of the hydrogenated fragments that, irrespective of the fragment sizes, actually shows an invariant planarity of the nanoflakes, which is clearly related to the hydrogen adsorption, causing the breaking of the $\mathrm{B}-\mathrm{B}$ and $\mathrm{N}-\mathrm{N}$ bonds.

The geometrical features characterizing both $\mathrm{H} / \mathrm{DVBN}$ $\mathrm{I}\{5,8,5\}_{\mathrm{R} 11}$ and H/DVBN-II $\{5,8,5\}_{\mathrm{R} 11}$ in the singlet state were very similar. Irrespective of the size of $\mathrm{BN} q-\mathrm{mn}$, the $\mathrm{N} 1-\mathrm{H}$ and $\mathrm{B} 1-\mathrm{H}$ bonds were 1.05 and $1.34 \AA$, respectively, while the dihedral angles $\theta(\mathrm{B} n)$ and $\theta(\mathrm{N} m)$, defined as before for the SW defect systems, were in both cases $180^{\circ}$, testifying the planarity of the BN framework.

These structures were also characterized by two supplementary bond arrangements, namely, $\mathrm{N} 2 \cdots \mathrm{H}-\mathrm{N} 1$ and $\mathrm{B} 2 \cdots$ $\mathrm{H}-\mathrm{B} 1$. The dotted bonds formalize auxiliary interactions, while the whole $\mathrm{N}$ and the $\mathrm{B}$ groupings, singly, recall what are classically called hydrogen and banana bonds, respectively. To these ones, regardless of the considered model, corresponded atomic distances, in the order, of ca. 1.6 and $1.5 \AA$, for the N... $\mathrm{H}$ and $\mathrm{B} \cdots \mathrm{H}$ systems.

The formation of these $\mathrm{H}$ bridges between $\mathrm{N}$ and $\mathrm{B}$ atomic pairs, with the closure of two six terms cycles, most likely, contributed to the stability of the planar arrangements of the hydrogenated nanoflakes. Moreover, the difference between the $\mathrm{B}-\mathrm{H}$ and $\mathrm{B} \cdots \mathrm{H}$ distances (ca. 10\%) suggests a substantial equivalence of these bonds. While the slightly larger difference observed among the $\mathrm{N}-\mathrm{H}$ and $\mathrm{N} \cdots \mathrm{H}$ bonds could be due to the presence of a slightly more stable configuration in the fragment, determined by little local symmetry deviations.

Therefore, on the one hand, these results would suggest a substantial equivalence between the H/DVBN-X $\{5,8,5\}_{R 11}$ and $\mathrm{H} / \mathrm{DVBN}-\mathrm{X}\{5,8,5\}_{\mathrm{R} 12}$ singlet state fragments and, on the other hand, they could represent the cause for the impossibility of isolating, at least by the here employed optimization algorithm, a structure where the $\mathrm{H}$ atom is adsorbed on one $\mathrm{N}$ site diagonally facing one $\mathrm{B}$ site. This analysis is supported by studies on $\mathrm{H}_{2}$ splitting occurring on topologically equivalent $\mathrm{N}$ vacancy defects, embedded in graphene-like fragments, ${ }^{59}$ that without exception showed almost isoenergetic $\mathrm{H}$ on the different $\mathrm{N}$ defects. ${ }^{22}$

The geometrical features characterizing both the H/DVBN$\mathrm{I}\{5,8,5\}_{\mathrm{R} 11}$ and $\mathrm{H} / \mathrm{DVBN}-\mathrm{II}\{5,8,5\}_{\mathrm{R} 11}$ triplet state fragments were also found to be very similar to each other, with the N1$\mathrm{H}$ and $\mathrm{B} 1-\mathrm{H}$ bond distances of 1.05 and $1.20 \AA$. Conversely, there was a slight difference in the dihedral $\theta(\mathrm{B} n)$ angles, which in the order resulted in $-24.5^{\circ}$ and $-26.0^{\circ}$ for the species-I and -II. These angle values presumably account for the higher energy of the triplet state that certainly is also connected to the shorter $\mathrm{B} 1-\mathrm{H}$ distance (with respect to the singlet case) and to the fact that the $\mathrm{H}$ atom is not shared between the two $\mathrm{B}$ atoms.
The energy involved in the hydrogenation, $\Delta E_{\mathrm{r}}$, was calculated considering both the DVBN-X $\{5,8,5\}_{R}$ fragments (with $\mathrm{X}=\mathrm{I}, \mathrm{II}$ ) as reactants and the corresponding $\mathrm{H} / \mathrm{DVBN}$ $\mathrm{X}\{5,8,5\}_{\mathrm{R} 11}$ hydrogenated fragments as products, all of them in the singlet state. The $\Delta E_{\mathrm{r}}$ values were -133.7 and $-206.7 \mathrm{~kJ}$ $\mathrm{mol}^{-1}$ for the reaction system-I and -II, respectively.

In order to test the curvature effects on the hydrogenation energetics, the DVBNNT $(12,12)$ fragment was hydrogenated in correspondence of both the B1IN1 and the B1IN2 pairs. Therefore, it is here important to specify that the model system in the ONIOM calculation of the whole DVBNNT $(12,12)$ species was a reconstructed $\{5,8,5\}$ fragment, which was pretty comparable with the DVBN-II $\{5,8,5\}_{\mathrm{R}}$ model.

The hydrogenation of the B1IN1 pair led to minima for both the singlet and the triplet multiplicity states. As in the case of the nanoflakes, the singlet was more stable than the triplet state by an energy difference of $-153.9 \mathrm{~kJ} \mathrm{~mol}^{-1}$. Incidentally, this difference is very similar to that calculated for the different multiplicity states, characterizing the H/DVBN-II $\{5,8,5\}_{\mathrm{R} 11}$ species. As already found for the nanoflake models, the hydrogenated B1IN2 pair, when in the nanotube, is an energy minimum just for the triplet state species.

The hydrogenation energy, $\Delta E_{\mathrm{r}}$, value calculated for the singlet state of the DVBNNT $(12,12)$ fragment was $-4.7 \mathrm{~kJ}$ $\mathrm{mol}^{-1}$. This smaller value, with respect to those found for the nanoflakes, is easily a consequence of the almost fixed cylindrical structure of the nanotube, which inhibits the formation of both the $\mathrm{N} 2 \cdots \mathrm{H}-\mathrm{N} 1$ and $\mathrm{B} 2 \cdots \mathrm{H}-\mathrm{B} 1$ arrangements discussed above.

3.3.3. $\mathrm{H}_{2}$ Splitting and Diffusion on Divacancy Defects. Taking into account the extreme endothermic behavior of the hydrogenated SW systems, the hydrogenation process was further analyzed solely for the BN-d defects, evaluating the $\mathrm{H}$ migration through the sites that characterize the divacancy defect arrangements. Furthermore, because the blocked curvature own of the BN nanotube even lessened the stability of the hydrogenated systems, it was decided to study the hydrogen diffusion, just considering singlet state species, only on the DVBN-II $\{5,8,5\}_{R}$ larger fragment, as shown in Figure 9.

Because the hydrogenated H/DVBN-II $\{5,8,5\}_{R 11}$ was the most stable fragment, it was at first hypothesized that the $\mathrm{H}_{2}$ molecule is split on the B1IN1 nonadjacent pair of the DVBN$\operatorname{II}\{5,8,5\}_{R}$ model. The activation barrier of this process resulted

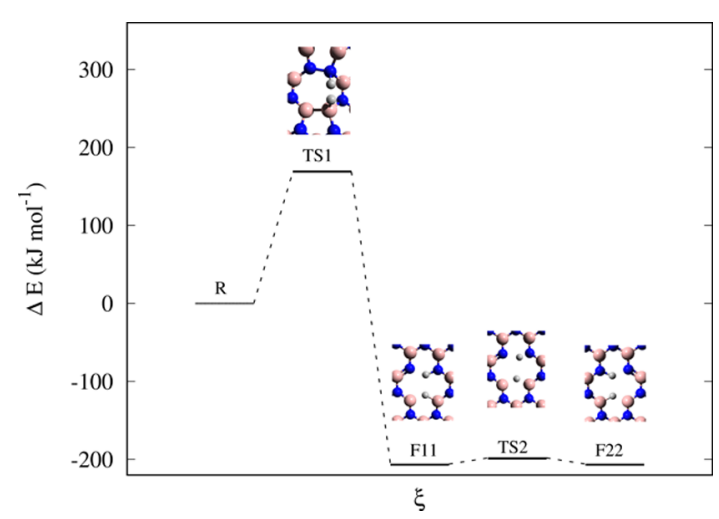

Figure 9. Energetic profile of the $\mathrm{H}_{2}$ fragmentation and diffusion on sites related to the $\mathrm{BN}-\mathrm{d}$ defect formation: $\xi$, reaction coordinates; $\mathrm{R}$, reagents; TS1, $\mathrm{H}_{2}$ splitting transition state; F11, hydrogenated $\mathrm{H} /$ DVBN-II $\{5,8,5\}_{\mathrm{R} 11}$ fragment; TS2, $(\mathrm{N} 1 \rightarrow \mathrm{N} 2) \mathrm{H}$ diffusion transition state; F22, hydrogenated $\mathrm{H} / \mathrm{DVBN}-\mathrm{II}\{5,8,5\}_{\mathrm{R} 22}$ fragment. 
in $169.1 \mathrm{~kJ} \mathrm{~mol}^{-1}$. The TS1 transition state geometry is characterized by a strong elongation in the N1-N2 bond (1.84 A) paralleled by the formation of the $\mathrm{B} 1-\mathrm{H}$ and $\mathrm{N} 1-\mathrm{H}$ bonds. Along with these local rearrangements, the nanoflake becomes planar. Starting from the so-formed H/DVBN-II $\{5,8,5\}_{\mathrm{R} 11}$, one $\mathrm{H}$ can diffuse from $\mathrm{N} 1$ to $\mathrm{N} 2$ with an activation barrier of 8.1 $\mathrm{kJ} \mathrm{mol}^{-1}$, while a slight adjustment of the $\mathrm{B} 2 \cdots \mathrm{H}-\mathrm{B} 1$ arrangement was observed. This transforms the starting fragment to the specular H/DVBN-II $\{5,8,5\}_{\mathrm{R} 22}$ isomer. The very low activation barrier suggests a kind of $\mathrm{H}$ shuttling between the paired neighboring $\mathrm{N}$ atoms that occur in the divacancy defects and straightforwardly supports the inference on the equivalence arising between the two $\mathrm{N}$ and the two $\mathrm{B}$ pairs, hence on the whole of the equivalence of the different $\mathrm{B} n \mathrm{IN} m$ pairs present in the $\mathrm{BN}-\mathrm{d}$ defect constellations.

In order to verify if the process above is conditioned by a redistribution of electronic charge density in the defective sites involved, $^{60}$ a Mulliken charge partitioning scheme has been applied to selected BN fragments, including the defective nanoflake formation and its hydrogenation in the analysis, as summarized in the following:

$$
\begin{aligned}
& \text { DVBN-II } \rightarrow \text { DVBN-II }\{585\}_{\mathrm{R}} \stackrel{\mathrm{H} 2}{\longrightarrow} \mathrm{TS}_{1} \rightarrow \mathrm{H} / \mathrm{DVBN} \\
& \quad-\mathrm{II}\{585\}_{\mathrm{R}}
\end{aligned}
$$

Table 5 shows that, besides one off-trend point [sites $\mathrm{N}(88) 2$ of species 1$]$, there are no consistent changes in the

Table 5. Mulliken Partitioning Scheme Characterizing the $\{585\}$ Site Environment of Pristine DVBN-II, Species 1, Reconstructed DVBN-II $\{585\}_{R}$, Species 2, TS1, Species 3, and Hydrogenated H/DVBN-II $\{585\}_{R}$, Species 4

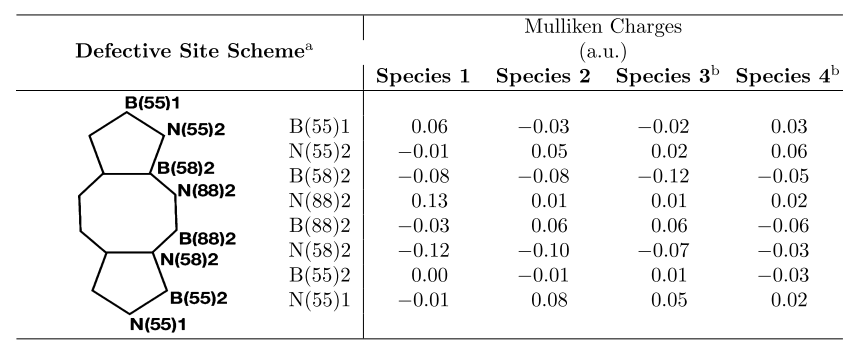

${ }^{a_{\text {The }}}$ generic label, $\mathrm{X}(n m) k$, indicates that the atom $\mathrm{X}, \mathrm{B}$ or $\mathrm{N}$, belongs to the $n$-membered ring $(n=m)$ or to the $n$-membered and $m$-membered rings $(n \neq m) ; k$ shows how many, 1 or 2 , of these atoms are present in the defective environment. By symmetry, there are in fact couples of topologically equivalent sites, which show almost equal Mulliken charges. For these couples of sites, the average charge values were reported. ${ }^{b}$ Species 3 and 4 are characterized by hydrogens interacting with $B$ and $N$ sites during the DVBN-II $\{585\}_{\mathrm{R}} \stackrel{\mathrm{H}_{2}}{\longrightarrow} \mathrm{H} / \mathrm{DVBN}-\mathrm{II}\{585\}_{\mathrm{R}}$ process. This, of course, can produce a certain degree of asymmetry in the properties of these pairs of atoms that however is, on the whole, never significant.

values of the Mulliken charges characterizing the defective sites of the $\{585\}$ environment after the reconstruction. There are actually no basic changes even after the introduction of hydrogen. Of course, some local modifications can be observed at the sites directly interacting with hydrogen, but no significant changes were noticed.

Finally, to study the effects of the hydrogen saturation on the defective $q$-mn $\mathrm{BN}$ environment, an additional $\mathrm{H}_{2}$ molecule was fragmented on the H/DVBN-X $\{5,8,5\}_{R}$ systems and analyzed in both the singlet and triplet states. The former showed to be systematically more stable irrespective of the considered species. In particular, the calculated $\Delta E_{\mathrm{r}}$ values in the singlet state individually were -278.9 and $-277.3 \mathrm{~kJ} \mathrm{~mol}^{-1}$ for the smaller and larger fragments. For the furtherhydrogenated $\mathrm{H} / \mathrm{DVBN}-\mathrm{II}\{5,8,5\}_{\mathrm{R}}$ model, the $\Delta E_{\mathrm{a}}$ value was calculated, which is equal to $29.3 \mathrm{~kJ} \mathrm{~mol}^{-1}$. These results confirm the strong stabilization, characterizing the hydrogen adsorption, and show a more affordable fragmentation of a second $\mathrm{H}_{2}$ molecule once the first molecular adsorption occurs. From these findings, it is clear that the first $\mathrm{H}_{2}$ desorbing molecule needs less energy with respect to the second one (ca. $69 \mathrm{~kJ} \mathrm{~mol}^{-1}$ ).

Keeping in mind that hydrogen desorption could also take place atomically ${ }^{61}$ and hypothesizing, for the sake of simplicity, that a desorption occurs in sequence from the pairs of $\mathrm{B}$ and $\mathrm{N}$ sites (or vice versa), ${ }^{a}$ it is observed that the second $\mathrm{H}_{2}$ molecule is more easily recomposed with respect to the first one, ca. $71 \mathrm{~kJ} \mathrm{~mol}^{-1}$, irrespective of the desorption sequence (the first desorption event from $\mathrm{B}$ and then from $\mathrm{N}$ or vice versa). It is also observed that it is always easier to remove the first $\mathrm{H}$ atom from the $\mathrm{B}$ site with respect to the $\mathrm{N}$ site, ca. 30 and $93 \mathrm{~kJ} \mathrm{~mol}^{-1}$, in the desorption of the first and second hydrogen pairs, respectively. It is finally observed that the desorption events of pairs of $\mathrm{H}$ atoms are on the whole more difficult than that of the corresponding $\mathrm{H}_{2}$ molecule; considering cumulative barrier energies, the differential values of the atomic pairs with respect to the molecular desorption are indeed ca. 375 and $235 \mathrm{~kJ} \mathrm{~mol}^{-1}$ for the first and second desorption processes, irrespective of the $\mathrm{H}$ atomic desorption sequence. However, the subsequent recomposition of the $\mathrm{H}_{2}$ molecule (from the couple of atoms) in the gas phase leads always to an energy gain (ca. $403 \mathrm{~kJ} \mathrm{~mol}^{-1}$ ), which straightforwardly bring the corresponding systems back to the whole energy conditions of the species involved in the molecular hydrogenation of the H/DVBN-II $\{585\}_{R}$ and DVBN-II $\{585\}_{\mathrm{R}}$ fragments, respectively. Taking into consideration these preliminary results, the atomic desorption followed by the formation of the $\mathrm{H}_{2}$ molecule with respect to the $\mathrm{H}_{2}$ molecular desorption thus appears energetically always favored but kinetically generally unsuitable.

\section{CONCLUSIONS}

Defective metal-free BN fragments have been identified as potential materials to be employed in processes involving the use or production of hydrogen. The local defects introduced for originating local electronic gradients potentially functional for catalytic use were either of SW or of Schottky (divacancy defect) type. Specifically, the fragmentation and diffusion of atomic hydrogen near the defective sites were studied. In order to verify the effects of the size and radius of curvature inherent in the BN species, the study was conducted on $q$-mns of different sizes and on nanotube fragments. This choice was heuristic, showing a considerable reshaping ability of the nanoflake molecular fragments, depending on the amount and nature of the hydrogen species interacting with the different defective BN sites, which could be connected with their specific activity. Given the local electronic manipulations, fundamental to the purpose of the work, an analysis was carried out of the spin-state effects on the different models, actually studied using the DFT approach, also employing ONIOM methods. The fragments characterized by SW defects show extremely endothermic processes and therefore do not 
seem useful candidates for a practical use. On the contrary, the local electronic changes specifically produced in the $\mathrm{BN} q$-mns by the presence of divacancy defects determine an exceptionally exothermic fragmentation of the molecular hydrogen on them and an almost not activated diffusion of the atomic hydrogen. This indeed would seem to suggest the potential use of these divacancy defective $\mathrm{BN}$ materials in hydrogen-based reactions. In particular, evaluating the strong lowering of the energy barrier in the $\mathrm{H}_{2}$ splitting when a second hydrogen molecule is adsorbed on an already hydrogenated divacancy defective environment, it is possible to infer that these systems deserve further investigations focused on their possible applications either as metal-free catalysts, potentially useful in dehydrogenation processes, or as dehydrogenation reagents, able to store hydrogen on them.

\section{ASSOCIATED CONTENT}

\section{S Supporting Information}

The Supporting Information is available free of charge on the ACS Publications website at DOI: 10.1021/acsomega.9b01445.

Cartesian coordinates for all the critical species involved in the analysis of the divacancy framed in the BN system and its hydrogenated congener (PDF)

\section{AUTHOR INFORMATION}

\section{Corresponding Author}

*E-mail: dario.duca@unipa.it. Phone: +39 091 23897975. Fax: +39091590015.

\section{ORCID $\odot$}

Remedios Cortese: 0000-0002-7232-8916

Dario Duca: 0000-0003-0281-8634

\section{Present Address}

${ }^{\dagger}$ Leiden Observatory, Leiden University, Niels Bohrweg 2, 2333 CA Leiden, The Netherlands.

\section{Notes}

The authors declare no competing financial interest.

\section{ACKNOWLEDGMENTS}

The authors thank Dr. Antonio Prestianni for his technical advices on the use of the computing resources of the CCCP research group. D.C. acknowledges financial support from the EU under the Horizon2020 Marie Skłodowska-Curie ITN EUROPAH (grant number 722346).

\section{ADDITIONAL NOTE}

${ }^{a}$ The atomic desorption processes, which will be presented in a subsequent work along with the dehydrogenation of different hydrocarbons and of their halogenic and alcoholic derivatives, also involve hydrogenated fragments having fundamental states with a spin multiplicity equal to 2 .

\section{REFERENCES}

(1) A "combo element" is defined as the combination of two elements belonging to the same period, one in the group $(n-x)$ and one in the group $(n+x)$, which are able to form compounds analogous to those of the element of the group $(n)$ that is found precisely in-between them in the periodic table.

(2) Novoselov, K. S.; Geim, A. K.; Morozov, S. V.; Jiang, D.; Zhang, Y.; Dubonos, S. V.; Grigorieva, I. V.; Firsov, A. A. Electric Field Effect in Atomically Thin Carbon Films. Science 2004, 306, 666-669.
(3) Geim, A. K.; Novoselov, K. S. The Rise of Graphene. Nat. Mater. 2007, 6, 183-191.

(4) Blase, X.; Rubio, A.; Louie, S. G.; Cohen, M. L. Stability and Band Gap Constancy of Boron Nitride Nanotubes. Europhys. Lett. 1994, 28, 335-340.

(5) Rubio, A.; Corkill, J. L.; Cohen, M. L. Theory of Graphitic Boron Nitride Nanotubes. Phys. Rev. B: Condens. Matter Mater. Phys. 1994, 49, 5081-5084.

(6) Blase, X.; Rubio, A.; Louie, S.; Cohen, M. L. Stability and Band Gap Constancy of Boron Nitride Nanotubes. Europhys. Lett. 1994, 28, 335-340.

(7) Zhang, Z.; Guo, W.; Dai, Y. Stability and Electronic Properties of Small Boron Nitride Nanotubes. J. Appl. Phys. 2009, 105, 084312.

(8) Mananghaya, M. R.; Santos, G. N.; Yu, D. Solubility of Aminotriethylene Glycol Functionalized Single Wall Carbon Nanotubes: A Density Functional Based Tight Binding Molecular Dynamics Study. J. Comput. Chem. 2019, 40, 952-958.

(9) Nagashima, A.; Tejima, N.; Gamou, Y.; Kawai, T.; Oshima, C. Electronic Structure of Monolayer Hexagonal Boron Nitride Physisorbed on Metal Surfaces. Phys. Rev. Lett. 1995, 75, 3918-3921.

(10) Pacilé, D.; Meyer, J. C.; Girit, Ç. Ö.; Zettl, A. The twodimensional phase of boron nitride: Few-atomic-layer sheets and suspended membranes. Appl. Phys. Lett. 2008, 92, 133107-133111.

(11) Tian, Y.; Wei, R.; Eichhorn, V.; Fatikow, S.; Shirinzadeh, B.; Zhang, D. Mechanical Properties of Boron Nitride Nanocones. J. Appl. Phys. 2012, 111, 104316-104320.

(12) Chopra, N. G.; Luyken, R. J.; Cherrey, K.; Crespi, V. H.; Cohen, M. L.; Louie, S. G.; Zettl, A. Boron Nitride Nanotubes. Science 1995, 269, 966-967.

(13) Zhi, C.; Bando, Y.; Tang, C.; Golberg, D.; Xie, R.; Sekiguchi, T. Large-scale fabrication of boron nitride nanohorn. Appl. Phys. Lett. 2005, 87, 063107-063114.

(14) Golberg, D.; Rode, A.; Bando, Y.; Mitome, M.; Gamaly, E.; Luther-Davies, B. Boron nitride nanostructures formed by ultra-highrepetition rate laser ablation. Diamond Relat. Mater. 2003, 12, 12691274.

(15) Lin, Y.; Williams, T. V.; Cao, W.; Elsayed-Ali, H. E.; Connell, J. W. Defect Functionalization of Hexagonal Boron Nitride Nanosheets. J. Phys. Chem. C 2010, 114, 17434-17439.

(16) Lehtinen, O.; Dumur, E.; Kotakoski, J.; Krasheninnikov, A. V.; Nordlund, K.; Keinonen, J. Production of Defects in Hexagonal Boron Nitride Monolayer Under Ion Irradiation. Nucl. Instrum. Methods Phys. Res., Sect. B 2011, 269, 1327-1331.

(17) Schmidt, T. M.; Baierle, R. J.; Piquini, P.; Fazzio, A. Theoretical Study of Native Defects in BN Nanotubes. Phys. Rev. B: Condens. Matter Mater. Phys. 2003, 67, 113407-113412.

(18) Zobelli, A.; Ewels, C. P.; Gloter, A.; Seifert, G. Vacancy Migration in Hexagonal Boron Nitride. Phys. Rev. B: Condens. Matter Mater. Phys. 2007, 75, 094104-0941011.

(19) Jin, C.; Lin, F.; Suenaga, K.; Iijima, S. Fabrication of a Freestanding Boron Nitride Single Layer and Its Defect Assignments. Phys. Rev. Lett. 2009, 102, 195505-195509.

(20) Shevlin, S. A.; Guo, Z. X. Hydrogen Sorption in Defective Hexagonal BN Sheets and BN Nanotubes. Phys. Rev. B: Condens. Matter Mater. Phys. 2007, 76, 024104-024115.

(21) Zobelli, A.; Ewels, C. P.; Gloter, A.; Seifert, G.; Stephan, O.; Csillag, S.; Colliex, C. Defective Structure of BN Nanotubes: From Single Vacancies to Dislocation Lines. Nano Lett. 2006, 6, 19551960.

(22) Cortese, R.; Ferrante, F.; Roggan, S.; Duca, D. N-Doped Carbon Networks: Alternative Materials Tracing New Routes for Activating Molecular Hydrogen. Chem.-Eur. J. 2015, 21, 38063814.

(23) Stephan, D. W. Frustrated Lewis Pairs. J. Am. Chem. Soc. 2015, 137, 10018-10032.

(24) Duca, D.; La Manna, G.; Rosa Russo, M. Computational studies on surface reaction mechanisms: ethylene hydrogenation on platinum catalysts. Phys. Chem. Chem. Phys. 1999, 1, 1375-1382. 
(25) Duca, D.; Varga, Z.; La Manna, G.; Vidóczy, T. s. Hydrogenation of acetylene-ethylene mixtures on Pd catalysts: study of the surface mechanism by computational approaches. Metal dispersion and catalytic activity. Theor. Chem. Acc. 2000, 104, 302311.

(26) Duca, D.; Barone, G.; Varga, Z. Hydrogenation of AcetyleneEthylene Mixtures on Pd catalysts: Computational Study on the Surface Mechanism and on the Influence of the Carbonaceous Deposits. Top. Catal. 2001, 72, 17-23.

(27) Prestianni, A.; Crespo-Quesada, M.; Cortese, R.; Ferrante, F.; Kiwi-Minsker, L.; Duca, D. Structure Sensitivity of 2-Methyl-3-butyn2-ol Hydrogenation on Pd: Computational and Experimental Modeling. J. Phys. Chem. C 2014, 118, 3119-3128.

(28) Crespo-Quesada, M.; Yoon, S.; Jin, M.; Prestianni, A.; Cortese, R.; Cárdenas-Lizana, F.; Duca, D.; Weidenkaff, A.; Kiwi-Minsker, L. Shape-Dependence of Pd Nanocrystal Carburization during Acetylene Hydrogenation. J. Phys. Chem. C 2015, 119, 1101-1107.

(29) Ferrante, F.; Prestianni, A.; Cortese, R.; Schimmenti, R.; Duca, D. Density Functional Theory Investigation on the Nucleation of Homo- and Heteronuclear Metal Clusters on Defective Graphene. J. Phys. Chem. C 2016, 120, 12022-12031.

(30) Nash, D. J.; Restrepo, D. T.; Parra, N. S.; Giesler, K. E.; Penabade, R. A.; Aminpour, M.; Le, D.; Li, Z.; Farha, O. K.; Harper, J. K.; Rahman, T. S.; Blair, R. G. Heterogeneous Metal-Free Hydrogenation over Defect-Laden Hexagonal Boron Nitride. ACS Omega 2016, 1, 1343-1354.

(31) Grant, J. T.; Carrero, C. A.; Goeltl, F.; Venegas, J.; Mueller, P.; Burt, S. P.; Specht, S. E.; McDermott, W. P.; Chieregato, A.; Hermans, I. Selective Oxidative Dehydrogenation of Propane to Propene Using Boron Nitride Catalysts. Science 2016, 354, 15701573.

(32) Meyer, N.; Devillers, M.; Hermans, S. Boron Nitride Supported Pd Catalysts for the Hydrogenation of Lactose. Catal. Today 2015, 241, 200-207.

(33) Schimmenti, R.; Cortese, R.; Ferrante, F.; Prestianni, A.; Duca, D. Growth of sub-nanometric palladium clusters on boron nitride nanotubes: a DFT study. Phys. Chem. Chem. Phys. 2016, 18, 17501757.

(34) Prestianni, A.; Cortese, R.; Ferrante, F.; Schimmenti, R.; Duca, D.; Hermans, S.; Murzin, D. Y. $\alpha$-d-Glucopyranose Adsorption on a Pd30 Cluster Supported on Boron Nitride Nanotube. Top. Catal. 2016, 59, 1178-1184.

(35) Cortese, R.; Schimmenti, R.; Prestianni, A.; Duca, D. DFT Calculations on Subnanometric Metal Catalysts: a Short Review on New Supported Materials. Theor. Chem. Acc. 2018, 137, 59-66.

(36) Mananghaya, M. R. Hydrogen saturation limit of Ti-doped BN nanotube with B-N defects: An insight from DFT calculations. Int. J. Hydrogen Energy 2018, 43, 10368-10375.

(37) Weber, M.; Lamboux, C.; Navarra, B.; Miele, P.; Zanna, S.; Dufond, M. E.; Santinacci, L.; Bechelany, M. Boron Nitride as a Novel Support for Highly Stable Palladium Nanocatalysts by Atomic Layer Deposition. Nanomaterials 2018, 8, 849.

(38) Torii, S.; Jimura, K.; Hayashi, S.; Kikuchi, R.; Takagaki, A. Utilization of hexagonal boron nitride as a solid acid-base bifunctional catalyst. J. Catal. 2017, 355, 176-184.

(39) Prestianni, A.; Ferrante, F.; Duca, D. $\mathrm{H}_{2}$ Hitting on Graphene Supported Palladium Cluster: Molecular Dynamics. Theor. Chem. Acc. 2017, 136, 6.

(40) Schimmenti, R.; Cortese, R.; Duca, D.; Mavrikakis, M. Boron Nitride-supported Sub-nanometer Pd 6 Clusters for Formic Acid Decomposition: A DFT Study. ChemCatChem 2017, 9, 1610-1620.

(41) Zhou, Y.; Lin, J.; Li, L.; Pan, X.; Sun, X.; Wang, X. Enhanced Performance of Boron Nitride Catalysts with Induction Period for the Oxidative Dehydrogenation of Ethane to Ethylene. J. Catal. 2018, $365,14-23$.

(42) Shi, L.; Wang, Y.; Yan, B.; Song, W.; Shao, D.; Lu, A.-H. Progress in Selective Oxidative Dehydrogenation of Light Alkanes to Olefins Promoted by Boron Nitride Catalysts. Chem. Commun. 2018, 54, 10936-10946.
(43) Venegas, J. M.; Grant, J. T.; McDermott, W. P.; Burt, S. P.; Micka, J.; Carrero, C. A.; Hermans, I. Selective Oxidation of n -Butane and Isobutane Catalyzed by Boron Nitride. ChemCatChem 2017, 9, 2118-2127.

(44) Dapprich, S.; Komáromi, I.; Byun, K. S.; Morokuma, K.; Frisch, M. J. A New ONIOM Implementation in Gaussian98. Part I. The Calculation of Energies, Gradients, Vibrational Frequencies and Electric Field Derivatives. J. Mol. Struct.: THEOCHEM 1999, 461$462,1-21$.

(45) Frisch, M. J.; Trucks, G. W.; Schlegel, H. B.; Scuseria, G. E.; Robb, M. A.; Cheeseman, J. R.; Scalmani, G.; Barone, V.; Mennucci, B.; Petersson, G. A.; Nakatsuji, H.; Caricato, M.; Li, X.; Hratchian, H. P.; Izmaylov, A. F.; Bloino, J.; Zheng, G.; Sonnenberg, J. L.; Hada, M.; Ehara, M.; Toyota, K.; Fukuda, R.; Hasegawa, J.; Ishida, M.; Nakajima, T.; Honda, Y.; Kitao, O.; Nakai, H.; Vreven, T.; Montgomery, J. A., Jr.; Peralta, J. E.; Ogliaro, F.; Bearpark, M.; Heyd, J. J.; Brothers, E.; Kudin, K. N.; Staroverov, V. N.; Kobayashi, R.; Normand, J.; Raghavachari, K.; Rendell, A.; Burant, J. C.; Iyengar, S. S.; Tomasi, J.; Cossi, M.; Rega, N.; Millam, J. M.; Klene, M.; Knox, J. E.; Cross, J. B.; Bakken, V.; Adamo, C.; Jaramillo, J.; Gomperts, R.; Stratmann, R. E.; Yazyev, O.; Austin, A. J.; Cammi, R.; Pomelli, C.; Ochterski, J. W.; Martin, R. L.; Morokuma, K.; Zakrzewski, V. G.; Voth, G. A.; Salvador, P.; Dannenberg, J. J.; Dapprich, S.; Daniels, A. D.; Farkas, Ö.; Foresman, J. B.; Ortiz, J. V.; Cioslowski, J.; Fox, D. J. Gaussian 09 Revision C.01. 2009; Gaussian Inc.:Wallingford CT, 2009.

(46) Zhao, Y.; Truhlar, D. G. The M06 suite of density functionals for main group thermochemistry, thermochemical kinetics, noncovalent interactions, excited states, and transition elements: two new functionals and systematic testing of four M06-class functionals and 12 other functionals. Theor. Chem. Acc. 2008, 120, 215-241.

(47) Rappe, A. K.; Casewit, C. J.; Colwell, K. S.; Goddard, W. A.; Skiff, W. M. UFF, a Full Periodic Table Force Field for Molecular Mechanics and Molecular Dynamics Simulations. J. Am. Chem. Soc. 1992, 114, 10024-10035.

(48) An, W.; Wu, X.; Yang, J. L.; Zeng, X. C. Adsorption and Surface Reactivity on Single-Walled Boron Nitride Nanotubes Containing Stone-Wales Defects. J. Phys. Chem. C 2007, 111, 14105-14112.

(49) McKay, H.; Wales, D. J.; Jenkins, S. J.; Verges, J. A.; de Andres, P. L. Hydrogen on Graphene Under Stress: Molecular Dissociation and Gap Opening. Phys. Rev. B: Condens. Matter Mater. Phys. 2010, 81, 075425-075431.

(50) Stephan, D. W. "Frustrated Lewis pairs": a concept for new reactivity and catalysis. Org. Biomol. Chem. 2008, 6, 1535-1539.

(51) Chase, P. A. Hydrogen and Amine Activation by a Frustrated Lewis Pair of a Bulky N-Heterocyclic Carbene and $\mathrm{B}\left(\mathrm{C}_{6} \mathrm{~F}_{5}\right)_{3}$. Angew. Chem., Int. Ed. 2008, 47, 7433-7437.

(52) Li, Y.; Zhou, Z.; Golberg, D.; Bando, Y.; Schleyer, P. v. R.; Chen, Z. Stone-Wales Defects in Single-Walled Boron Nitride Nanotubes: Formation Energies, Electronic Structures, and Reactivity. J. Phys. Chem. C 2008, 112, 1365-1370.

(53) Letardi, S.; Celino, M.; Cleri, F.; Rosato, V. Atomic hydrogen adsorption on a Stone-Wales defect in graphite. Surf. Science 2002, 496, 33-38.

(54) Saito, Y.; Maida, M. Square, Pentagon, and Heptagon Rings at BN Nanotube Tips. J. Phys. Chem. A 1999, 103, 1291-1293.

(55) Sinthika, S.; Kumar, E. M.; Surya, V.; Kawazoe, Y.; Park, N.; Iyakutti, K.; Thapa, R. Activation of $\mathrm{CO}$ and $\mathrm{CO}_{2}$ on Homonuclear Boron Bonds of Fullerene-Like BN Cages: First Principles Study. Sci. Rep. 2015, 5, 17460.

(56) Miller, M.; Owens, F. J. Defect Induced Distortion of Armchair and Zigzag Graphene and Boron Nitride Nanoribbons. Chem. Phys. Lett. 2013, 570, 42-45.

(57) Rogers, K. M.; Fowler, P. W.; Seifert, G. Chemical Versus Steric Frustration in Boron Nitride Heterofullerene Polyhedra. Chem. Phys. Lett. 2000, 332, 43-50.

(58) Cortese, R.; Schimmenti, R.; Ferrante, F.; Prestianni, A.; Decarolis, D.; Duca, D. Graph-Based Analysis of Ethylene Glycol 
Decomposition on a Palladium Cluster. J. Phys. Chem. C 2017, 121, 13606-13616.

(59) Mananghaya, M. R.; Santos, G. N.; Yu, D.; Stampfl, C. Hydrogen Adsorption on Nearly Zigzag-Edged Nanoribbons: A Density Functional Theory Study. Sci. Rep. 2017, 7, 15727.

(60) Si, M. S.; Li, J. Y.; Shi, H. G.; Niu, X. N.; Xue, D. S. Divacancies in Graphitic Boron Nitride Sheets. Europhys. Lett. 2009, 86, 46002.

(61) Nguyen, H. T.; Huynh, L. K.; Truong, T. N. Migration and Desorption of Hydrogen Atom and Molecule on/from Graphene. Carbon 2017, 121, 248-256. 